Çukurova Üniversitesi Mühendislik Fakültesi Dergisi, 36(3), ss. 625-636, Eylül 2021

Cukurova University Journal of the Faculty of Engineering, 36(3), pp. 625-636, September 2021

\title{
Lift Coefficient Estimation of a Delta Wing Under the Ground Effect Using Artificial Neural Network
}

\author{
Sergen TÜMSE ${ }^{1}$, Mehmet BILLGILI'², Beşir ŞAHİN*1 \\ ${ }^{1}$ Çukurova University, Faculty of Engineering, Department of Mechanical Engineering, Adana \\ ${ }^{2}$ Cukurova University, Faculty of Ceyhan Engineering, Department of Mechanical Engineering, \\ Adana
}

Geliş tarihi: 17.05.2021 Kabul tarihi: 13.09.2021

\begin{abstract}
The estimation of the lift coefficient, $C_{L}$ of a non-slender delta wing under the ground effect, is performed by employing an artificial neural network (ANN). The purpose of the study is to estimate the lift coefficient, $C_{L}$ acting on the delta wing for the ground distance $h / c=0.4$ by utilizing the actual lift coefficient, $C_{L}$ for the ground distances $h / c=1,0.7,0.55,0.25$ and 0.1. In this ANN model, the angle of attack, $\alpha$ and ground distance, $h / c$ were used as input parameters and lift coefficients, $C_{L}$ as the output parameter. While mean absolute percentage error (MAPE) and root mean squared error (RMSE) were found as $1.60 \%$ and 0.0114 in the testing stage, they were calculated as $1.77 \%$ and 0.01 in the training stage. Hence, this investigation shows that the lift coefficient, $C_{L}$ of the delta wing in ground effect can be correctly estimated by developing an ANN model.
\end{abstract}

Keywords: Artificial neural network, Delta wing, Ground effect, Lift coefficient

\section{Yer Etkisi Altındaki Delta Kanat Üzerinde Oluşan Taşıma Katsayısının Yapay Sinir Ă̆ı Kullanılarak Tahmin Edilmesi}

Öz

Bu çalışmada, yapay sinir ağı kullanılarak, yer etkisi altında olan düşük süpürme açısına sahip delta kanat üzerindeki taşıma katsayının, $C_{L}$ tahmini yapılmıştır. Çalışmanın amacı boyutsuzlaştırılmış yer mesafesinin, $h / c=1,0,7,0,55,0,25$ ve 0.1 olduğu durumlardaki gerçek taşıma katsayıları kullanılarak, boyutsuz yer mesafesinin, $h / c=0.4$ olduğu durumdaki taşıma katsayısını tahmin etmektir. Oluşturulan yapay sinir ağı modelinde, hücum açısı, $\alpha$ ve boyutsuzlaştırılmış yer mesafesi, $h / c$ girdi parametreleri olarak kullanılmış, taşıma katsayısı, $C_{L}$ ise çıktı parametresi olarak kullanılmıştır. Oluşturulan yapay sinir ağı modelinin eğitimi aşamasında, ortalama mutlak yüzde hata (MAPE) ve kök ortalama kare hatası (RMSE) sırasıyla \%1,60 ve 0,0114 olarak hesaplanırken, test aşamasında bu değerler sırasıyla \%1,77 ve 0,01 olarak hesaplanmıştır. Sonuç olarak bu çalışma, yapay sinir ağı kullanılarak yer etkisi altında olan delta kanat üzerindeki taşıma katsayısının, $C_{L}$ doğru bir şekilde tahmin edilebileceğini göstermiştir.

Anahtar Kelimeler: Yapay sinir ağı, Delta kanat, Yer etkisi, Taşıma katsayısı

*Corresponding author (Sorumlu yazar): Beşir ŞAHIN, bsahin@cu.edu.tr 


\section{INTRODUCTION}

Non-slender delta wings are usually employed in Unmanned Air Vehicles, Micro Air Vehicles, and fighter crafts due to high maneuver capacity even at high angles of attacks. Two counter-rotating leading-edge vortices can identify the flow structure around delta wings that occurs symmetrically with respect to the delta wing's axis. There are a lot of studies and excellent reviews about vortical flow structure and aerodynamic characteristics of delta wing such as Gursul et al. [1], Ol and Gharib [2] and Gursul et al. [3].

The lift coefficient, $C_{L}$, is a dimensionless number that engineers and researchers utilize to model whole complex dependencies of shape, inclination and some flow conditions [4]. It denotes the ratio of the lift force on a kind of aircraft to the force generated by the multiplication of dynamic pressure and planform area of the body. It is a very important coefficient because it affects the aerodynamic performance of an aircraft, stall phenomena and flight stability. The stall is a very important parameter that affects aerodynamic efficiency, the performance, and stability of aircraft. The lift coefficient, $C_{L}$, gets higher by an increasing angle of attack and when the vortices start to break on a very close region to the apex of the wing the lift coefficient, $C_{L}$ attenuates by an increasing angle of attack. This situation is known as a stall. Moreover, maximum lift coefficient, $C_{L}$ determines the minimum speed at which an airplane can fly. So that reason, the measurement, and interpretation of the lift coefficient are very significant. Researchers generally measure the lift coefficient, $C_{L}$ by utilizing models in a wind tunnel. In the wind tunnel, the lift coefficient, $C_{L}$ can be measured by setting the velocity, density, and planform area of the body. The lift coefficient, $C_{L}$, includes the influences of air viscosity and compressibility. To accurately measure the lift coefficient, we must ensure that the influence compressibility and air viscosity are identical between the measurement and prediction case. On the contrary case, the prediction will not be accurate. The lift coefficient, $C_{L}$ occurs due to the pressure difference between the upper and lower surfaces of the delta wing. When an angle of attack, $\alpha$ is introduced to the delta wing, there will be a pressure difference between suction and pressure surfaces of the delta wing thus lift force is developed on the surface of the wing. The lift coefficient, $C_{L}$ can be increased or decreased by altering the angle of attack, $\alpha$ the shape of the model, and the velocity of the flow. Furthermore, the lift coefficient, $C_{L}$ on an aircraft changes with time for the same angle of attack, flow velocity and model geometry due to unsteady and complex flow structures as well as an irregular breakdown of vortices.

One of the most critical stages of the whole flight of an aircraft is the take-off and landing conditions. Because during the take-off and landing procedures, the flow physics and aerodynamic properties of an aircraft significantly alter from the critical characteristics of the unbounded flow region. During the take-off and landing stages, there is an inevitable interaction between the ground surface and the lower surface of the wing. So that reason, it is vitally important to investigate, understand and interpret the ground effect on the aerodynamics of aircraft. Even though most of the studies related to the structure of vortical flow and aerodynamic performance of delta wings are present in the literature, there aren't enough studies about the ground effect on the aerodynamic characteristics of delta wings. In the investigation of Kawazoe and Morita [5], as the delta wing approaches the ground, lift and drag coefficients, $C_{L}$ and $C_{D}$ augment, and rolling moment coefficient, $C_{M}$ are effected by the existence of the ground effect, particularly at higher $\alpha$ 's. According to Lee et al. [6], lift and drag coefficients, $C_{L}$ and $C_{D}$, were detected to increase by increasing anhedral as the distance between the ground and trailing edge of the anhedraled reversed delta wing gets smaller. Tumse et al. [7] concluded that lift and drag coefficients, $C_{L}$ and $C_{D}$, get higher with descending from the unbounded flow region under the ground effect at each angle of attack. According to them, the most effective dimensionless ground distance normalized by chord length, $h / c$ is 0.1 in terms of the aerodynamic performance since the highest $C_{L} / C_{D}$ ratio is 
acquired at $h / c=0.1$. An increase in aerodynamic performance developed by the ground effect can be interpreted in the ram pressure effect caused by the ground effect, which is the stagnation of air between the ground and the wing surface. According to Lee and Ko [8], lift enhancement was observed to be highest at lower angles of attack and ground distances, $h / c$ and this augmentation deteriorates by increasing $h / c$ and $\alpha$. Qu et al. [9] pointed out that lift, drag and nose-down moment coefficient gets higher with reducing ground proximity, $h / c$. According to them, the induced drag attenuates since the forming of weak wing-tip vortices and movement of vortices far away from the wing surface. Ahmed et al. [10] emphasized that the lift coefficient augments when the distance between wing and ground reduces at high angles of attack, $\alpha$ due to the RAM pressure effect and air cushion between airfoil surface and ground. But at low $\alpha, C_{L}$ deteriorates as ground distance, $h / c$ reduces due to the passage of converging-diverging flow in the region between airfoil and ground surfaces.

In order to reduce the number of a necessary experiment like pressure and force measurements in the wind tunnel and improve the control system, an artificial neural network (ANN) is an encouraging model due to the significant learning capability for linear and nonlinear systems. The aerodynamic characteristics of the aircraft equipped with various kinds of wings and the impacts of the flow control methods play a significant position in wind tunnel investigations. In these investigations, it is necessary to carry out a number of experiments such as the lift force, drag force, pressure and velocity measurements. Due to these high number of experiments, time, and cost requirements, researchers are encouraged to perform numerical and theoretical studies. The artificial neural network (ANN), which is one of the most important ones among these numerical studies, attracts much attention because of its ability to model complicated nonlinear systems [11-13].

In fluid mechanics, artificial neural networks are generally employed in Particle Image Velocimetry (PIV) measurements [14-16] and flow control applications [17-19]. Akbiyik and Yavuz [20] developed an ANN model to estimate the lift and drag coefficients, $C_{L}$, and $C_{D}$ on the NACA 2415 airfoil with and without plasma actuators. According to their study, the maximum error of lift and drag coefficients, $C_{L}$ and $C_{D}$ prediction, was $23.705 \%$ and $12.84 \%$. Moreover, they stated that the developed ANN model could be successfully used to estimate aerodynamic coefficients of the airfoil without the necessity of comprehensive experimental studies. In the study of Sarioglu et al. [21], the drag forces of a truck trailer equipped with a spoiler were predicted by an artificial neural network (ANN). They computed the mean absolute percentage error (MAPE) as $2.24 \%, 3.75 \%$ and $4.58 \%$ during training, validation, and testing stages, respectively, in the estimation of drag forces. A neural network could correctly learn the aerodynamic behavior of a delta wing having a sweep angle of $\Lambda=70^{\circ}$ under large-amplitude pitch oscillations [22]. Rokhsaz and Steck [23] revealed that the extremely nonlinear aerodynamic characteristics of an aircraft could be generalized with enough correctness for design objectives. Even though the neural network can be successfully generalized the aerodynamic properties in design and analysis problems, they seem deficient in terms of robustness for the characteristics of dynamic systems. Alkhedher and Al-Aribe [24] developed neural networks and an adaptive neuro-fuzzy logic interference system to estimate the pitching moment and aerodynamic normal force coefficients of different shaped wing aircraft under high angles of attack. Based on the comprehensive analysis of suggested prediction methods, the ANN demonstrated lower mean squared errors during modeling and testing stages. In the study of Gomec and Canibek [25] feed forward neural network (MLP) model having four layers together with two hidden layers was established and approved. According to their model, the Levenberg-Marquart backpropagation method was used as a training algorithm. In this study, Mach number, angle of attack, side slip angle was used in the input layer and drag force, lift force, side and roll moment was used in the output layer. 
Ignatyev and Khrabrov [26] developed a neural network model to predict the aerodynamic characteristics of canard aircraft at high angles of attack. The aircraft is equipped with leading-edge extension (LEX) and a canard surface with a high sweep angle. In this study, several approaches were carried out to estimate the aerodynamic performance of canard aircraft. They stated that recurrent neural network (RNN) trained bayesian regularization heteroscedastic data (BRHD) algorithm demonstrated that better conclusions regarding estimation ability compared to the neural network (NN) trained one. Moreover, the generalization ability of RNN was found to be better compared to NN one. Secco et al. [27] evaluated the various ANN architectures to predict aerodynamic coefficients on wing-body combinations constituted of generic airfoils. In this study, many numbers of data, nearly 100.000 to train and develop the ANN model. The number of neurons in ANN architecture was determined regarding the minimum mean squared error. According to this study, the mean absolute error (MAPE) was calculated as 0.0041 for the estimation of lift coefficient, $C_{L}$, and computation cost gets reduced by generated ANN model compared to computational fluid dynamics (CFD). Rai and Madavan [28] developed a neural network to estimate the aerodynamic characteristics of turbomachinery airfoils. In this study, pressure distribution data were used during the training process. They revealed that the neural network could be accurately used for the design of the airfoil.

The purpose of this investigation is to estimate the lift coefficient, $C_{L}$ of a non-slender delta wing under the ground effect by an artificial neural network (ANN) and to report the estimation capability of the developed ANN model for this kind of application.

\section{MATERIAL VE METHOD}

\subsection{Experimental Setup of Lift Coefficient Measurements}

The measurement of lift coefficients, $C_{L}$, was carried out in a wind tunnel with a square cross- section of $570 \mathrm{~mm} \times 570 \mathrm{~mm} \times 1000 \mathrm{~mm}$. This wind tunnel has a turbulence intensity of smaller than $0.1 \%$ [29]. By using a vibration suppressor, the vibrations from the fan are eliminated. The engine of the fan, which provides flow in the tunnel has a power of $4 \mathrm{~kW}$ and has a diameter of $700 \mathrm{~mm}$. The air inside the tunnel is discharged from the outlet hose into the atmosphere. Telemecanique Altivar 17 brand $(11 \mathrm{~kW})$ frequency converter control unit is utilized to obtain the desired airspeed within the range of $0-50 \mathrm{~Hz}$. The lift coefficient, $C_{L}$ measurement was performed at angles of attack within range of $2^{\circ} \leq \alpha \leq 29^{\circ}$ with an interval of $3^{\circ}$. The $C_{L}$ was computed according to Equation 1.In Equation 1, where $F_{L}$ is measured lift force of the delta wing, $\rho$ is the density of the fluid which is equal to $\rho=1 \mathrm{~kg} / \mathrm{m}^{3}$ at measurement condition, $U_{\infty}$ is the velocity of the fluid flow which is equal to $U_{\infty}=16.57 \mathrm{~m} / \mathrm{s}$ and $\mathrm{A}$ is the planform area of the wing, $A=0.5 \times b \times c$ where $b$ and $c$ is the span and chord length of the wing, respectively. Akbiyik et al. [30] computed the uncertainty of force measurement in the same wind-tunnel utilizing the identical measurement techniques for similar geometry with this investigation is nearly $\pm 5 \%$. The Reynolds number was handled as $\mathrm{Re}=1.296 \times 10^{5}$ based on the chord length of the wing. The maximum blockage ratio which is described as the proportion of wing's frontal area to the crosssectional area of the wind tunnel was calculated as $6 \%$.

$$
\mathrm{C}_{\mathrm{L}=} \frac{\mathrm{F}_{\mathrm{L}}}{0.5 \rho \mathrm{U}_{\infty}^{2} \mathrm{~A}}
$$

In this study, the distance between wing and ground, $h$, is nondimensionalized with the chord length, $c$ of the wing. The normalized ground distances, $h / c=1,0.7,0.55,0.4,0.25$ and 0.1 were used. Actually, the normalized ground distance, $h / c=1$, corresponds to the out-of-ground effect region, in other words, the ground-free case. The ground-free case is a circumstance that happens as an aircraft flies in the unbounded flow area which is outside of the region where the ground effect is felt. For detailed information about this subject and the schematic demonstration of the experimental setup, please refer to Tumse et al. [7]. The upper section 
of the wind tunnel was used to represent the ground. In lift coefficient measurements, the Reynolds number was taken as $\mathrm{Re}=1.296 \times 10^{5}$ with corresponding free-stream air velocity, $U_{\infty}=16.57$ $\mathrm{m} / \mathrm{s}$. The chord length of the wing used in this study is $14 \mathrm{~cm}$. Also, the wing has a sweep angle of $\Lambda=40^{\circ}$ thickness of $t=5$ with $45^{\circ}$ sharp leading-edges. The schematic representation of this delta wing and input parameters for $\mathrm{ANN}, h$, and $c$ are demonstrated in Figure 1.

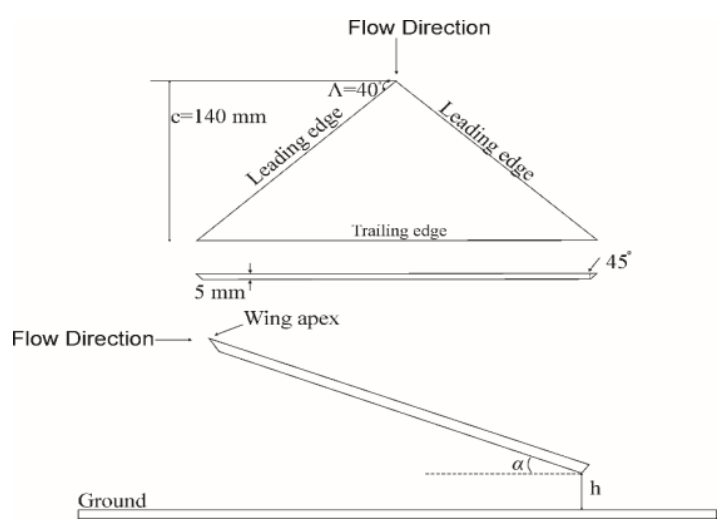

Figure 1. The schematic representation of the delta wing and input parameters of $\mathrm{ANN}, h$ and c

\subsection{Artificial Neural Network}

An artificial neural network is encouraged from the human neural network, as stated by Bishop [31]. A neural network can be regarded as a mathematical function changing nonlinearly that supplied a connection between input and output variables. ANN is a highly nonlinear model that is simple to utilize and recognize compared to statistical methods. It is a non-parametric model whereas most statistical methods are a parametric model that requires an advanced background of statistics. ANN is applied when one has minor or even no information on the structure and form of the input and output mapping. It generally can supply more flexibility in fitting non-linear mapping in high dimensional datasets than curve fitting or regression methods. The ANN model can be carried out accurately in various areas of mathematics, meteorology, medicine, thermodynamic applications, economics, robotic controls, heat and electrical load predictions, and many other fields [32-34]. The structure of the developed ANN model, which is known as Feed Forward Neural Network, is demonstrated in Figure 2. This generated ANN model is constituted of input, hidden, and output layers. Output value can be computed with respect to Equation 1.

$\mathrm{F}=\mathrm{f}\left(\mathrm{a}+\sum_{1}^{3} \mathrm{v}_{\mathrm{j}}+\left[\sum_{1}^{2} \mathrm{~g}\left(\mathrm{w}_{\mathrm{ij}} \mathrm{x}_{\mathrm{i}}+\mathrm{b}_{\mathrm{j}}\right)\right]\right)$

In Equation 2, $F$ is the predicted value, $\mathrm{a}$ is the output's bias value, $v_{j}$ is the weight for the value of output, $w_{i j}$ is the weight for the input layer, $b$ input's bias value, and $x$ is the variable for the input. The activation function of the input and output are denoted as $f$ and $g$ in Equation 2. The angle of attack, $\alpha$, and normalized ground distance, $h / c$ are the input parameters, whereas lift coefficient, $C_{L}$ is the output parameter of the generated ANN model. A total of 60 data is utilized for the training and testing process in the developed ANN model. The 50 data of these 60 data was used in the training process, whereas the rest for the testing process. The logistic sigmoid function (logsig) was used as an activation function in the hidden layer, whereas the linear transfer function (purelin) was employed as an activation function in the output layer. The expressions of logsig and purelin functions are demonstrated in Equations 3 and 4, respectively. The Levenberg-Marquart (LM) learning algorithm was employed in this simulation. In this study, a different number of neurons from 2 to 10 in the hidden layer was tested, and the best one for the prediction of lift coefficient in terms of MAPE, MAE, and RMSE was selected. The best results for the prediction of lift coefficient, $C_{L}$ were acquired when the number of neurons is 3 .

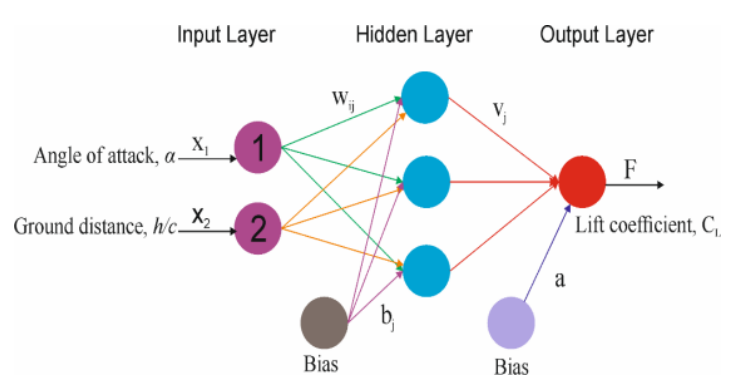

Figure 2. The structure of the developed ANN model 
$\mathrm{f}(\mathrm{a})=\frac{1}{1+\mathrm{e}^{-\mathrm{a}}}$

purelin $(a)=a$

\subsection{Accuracy Assessment of Estimated Parameters}

Mean absolute percentage error (MAPE) is a measure of closeness of estimated value to the actual value. Sometimes the MAPE can be stated as a percentage. It generally expresses the error of forecasting.

$\mathrm{MAPE}=\frac{\sum_{\mathrm{t}=1}^{\mathrm{n}}\left|\frac{\mathrm{A}_{\mathrm{t}}-\mathrm{F}_{\mathrm{t}}}{\mathrm{A}_{\mathrm{t}}}\right|}{\mathrm{n}} \times 100$

where $A$ is the actual value and $F$ is the forecasting value.

The mean absolute error (MAE) states the absolute error between predicted and real values. It is computed as the ratio of the sum of the difference between predicted and real values to the number of observations.

$\mathrm{MAE}=\frac{\sum_{\mathrm{t}=1}^{\mathrm{n}}\left|\mathrm{A}_{\mathrm{t}}-\mathrm{F}_{\mathrm{t}}\right|}{\mathrm{n}}$
The root mean square error (RMSE) is defined as the root of the mean square error which is the ratio of the sum of the square of the difference between predicted and real values to the number of observations.

$$
\mathrm{RMSE}=\sqrt{\frac{\sum_{\mathrm{t}=1}^{\mathrm{n}}\left(\mathrm{A}_{\mathrm{t}}-\mathrm{F}_{\mathrm{t}}\right)^{2}}{\mathrm{n}}}
$$

\section{RESULTS AND DISCUSSION}

Figure 3 represents the comparison between measured and estimated values of lift coefficient, $C_{L}$ with the angle of attack, $\alpha$ in case of ground distance, $h / c=0.4$ during the testing period. As inferred from this Figure, the estimated lift coefficient values, $C_{L}$ by ANN model, demonstrates an almost identical trend with experimentally measured ones. For example, while the lift coefficient, $C_{L}$ is experimentally measured as $0.4296,0.7532$, and 0.7177 at angles of attack, $\alpha=8^{\circ}, 17^{\circ}$ and $26^{\circ}$, respectively, they estimated as $0.4456,0.7527$ and 0.7048 , respectively by the developed ANN model. So, it can be said that the prediction performance of generated ANN model is very good during the testing period which includes the case of $h / c=0.4$.

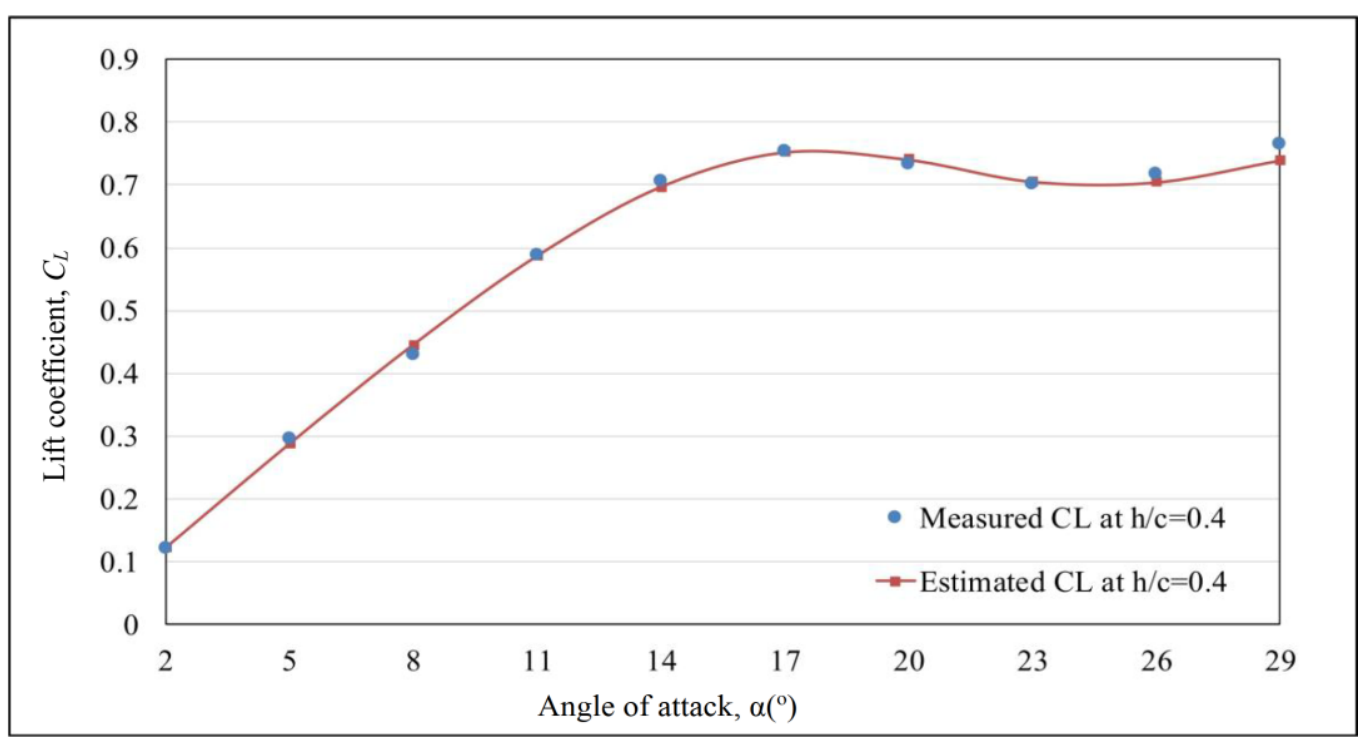

Figure 3. Comparison of actual and predicted lift coefficients, $C_{L}$ of a non-slender delta wing in case of ground distance, $h / c=0.4$ during the testing process 
The performance values such as MAPE, RMSE, and MAE for the estimation of lift coefficient, $C_{L}$ in case of normalized ground distance, $h / c=0.4$ during the testing case are demonstrated in Table 1. MAPE, MSE, and MAE are displayed in order to assess the estimation accuracy of generated ANN model. As reported by Lewis [34], the estimation assessment is rather correct if the value of MAPE is smaller than $10 \%$. As seen in Table 1, the MAPE value is $1.6 \%$ for the estimation of lift coefficient, $C_{L}$ in case of ground distance, $h / c=0.4$. So, it denotes that the generated ANN model has excellent accuracy. It should be mentioned that if the value of RMSE equals 0 or very close to 0 , the estimation performance is rather correct. As observed in Table 1 , the value of RMSE is 0.0114 . So, it can be said that the error between real and estimated values is very low. As seen in Table 1, the value of MAE is found as 0.0086 during the prediction of lift coefficient, $C_{L}$ in the case of $h / c=0.4$. This MAE value can be regarded as highly acceptable for the prediction of lift coefficient, $C_{L}$. Figure 4 shows the correlation between the experimental and estimated values of lift coefficient, $C_{L}$, with the angle of attack, $\alpha$, generated by the ANN model. Regression value, $R$ specifies the relationship between measured and estimated lift coefficient, $C_{L}$. As seen in Figure 4, the regression value, $\mathrm{R}$, is almost equal to 1 ; hence, the developed ANN model demonstrates excellent consistency with experimentally measured lift coefficient, $C_{L}$.

Table 1. The values of MAPE, RMSE, and MAE for the estimation of lift coefficient, $C_{L}$ in case of normalized ground distance, $h / c=0.4$ during the testing case

\begin{tabular}{|c|c|c|}
\hline \multicolumn{3}{|c|}{ TESTING (h/c=0.4) } \\
\hline MAPE & RMSE & MAE \\
\hline $1.60 \%$ & 0.0114 & 0.0086 \\
\hline
\end{tabular}

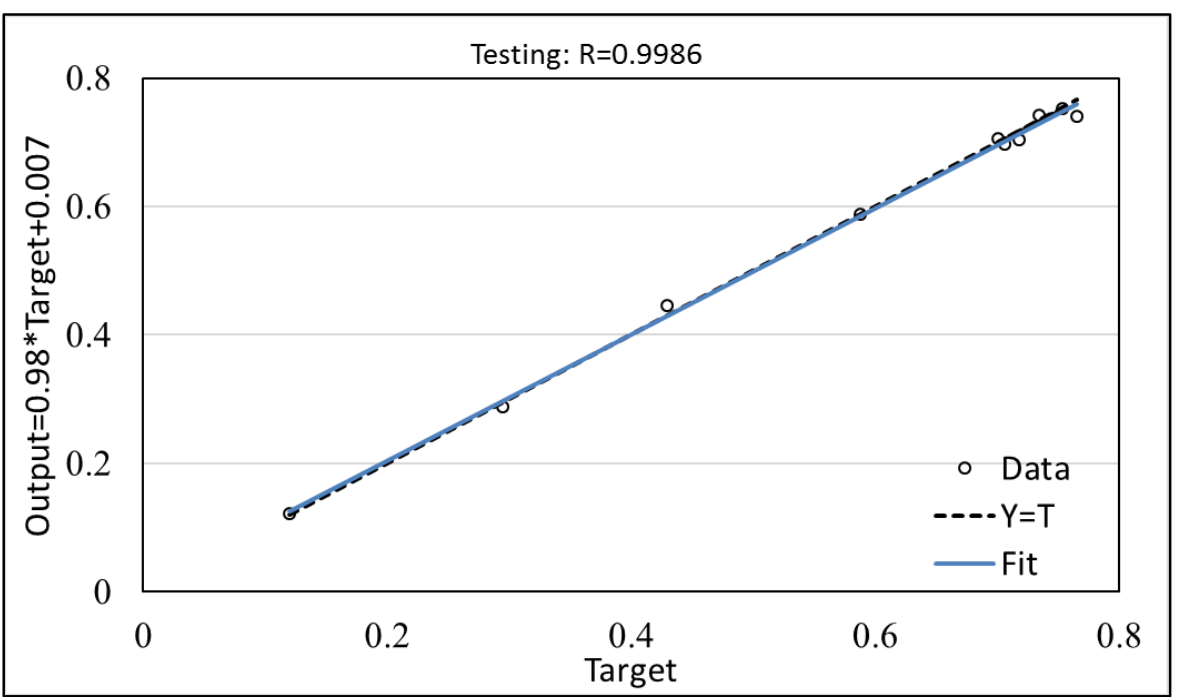

Figure 4. Relation between actual and predicted values of lift coefficient, $\mathrm{C}_{\mathrm{L}}$ for testing case

The comparison of predicted and measured lift coefficients, $C_{L}$ of a $40^{\circ}$ swept delta wing under various ground distances, $h / c$ during the training stage is demonstrated in Figure 5. As seen in Figure 5 , the predicted lift coefficient, $C_{L}$ generated with ANN model are noticeably linked with measured ones demonstrating considerably correct results.
The estimated lift coefficients, $C_{L}$ overlap with experimentally measured lift coefficients, $C_{L}$ independent of angles of attack during the training stage. For example, at $h / c=0.7$, while lift coefficient, $C_{L}$ was experimentally measured as 0.568, 0.701 and 0.7 at $\alpha=11^{\circ}, 20^{\circ}$ and $29^{\circ}$, respectively, they are predicted as $0.571,0.7$ and 
0.688 at $\alpha=11^{\circ}, 20^{\circ}$ and $29^{\circ}$, respectively by developed ANN model. As observed from Figure 5, the lift coefficient, $C_{L}$ augments by reducing normalized ground distance, $h / c$. For instance, at $\alpha=14^{\circ}$, while $C_{L}$ is equal to 0.673 for $h / c=0.7$, it is found as $0.741,0.836$ for $h / c=0.25$ and 0.1 , respectively. The lift increment can be attributed to the ground effect induced RAM pressure and dynamic air cushion in the region between the ground surface and wing's pressure surface. As noticed in Figure 5, the maximum lift coefficient is acquired at $\alpha=17^{\circ}$ and the $C_{L}$ starts to decrease beyond $\alpha=17^{\circ}$ thus, it can be said that the stall phenomena takes place after $\alpha=17^{\circ}$. While the $C_{L}$ attenuates up to the $\alpha=23^{\circ}$, it again increases when the angle of attack alters from $\alpha=23^{\circ}$ to $\alpha=26^{\circ}$ and $29^{\circ}$. This situation can be interpreted to the highlevel fluid-structure interactions that end up with remarkable lift augmentation in the post-stall region which is also reported in the excellent review of Gursul et al. [1]. This flow physics is a specific property of non-slender delta wings. The regression value, $R$ which denotes the relation of real and estimated lift coefficient, $C_{L}$ was found to very close to the 1 for all ground distances, $h / c=1,0.7,0.55$, 0.25 and 0.1 during the training stage as observed from Figures 6 and 7. So, it can be said that the estimation performance of generated ANN model is very accurate during the training stage. Table 2 displays the assessment of the performance of the generated ANN model via MAPE, RMSE, and MAE values during the training stage. Moreover, in Table 3, these performance values are given separately for all ground distances, $h / c$ constituting the training stage. Table 2 and Table 3 show that the MAPE, RMSE, and MAE are within the acceptable ranges. The MAPE value in the training stage which consists of $h / c=1,0.7,0.55,0.25$, and 0.1 , is $1.77 \%$ and higher than the MAPE value in the testing stage consisting of $h / c=0.4$ which has already computed as \%1.6. When Table 3 is examined carefully, it can be observed that the MAPE, RMSE, and MAE values get higher with reducing ground distances, $h / c$, during the training process. For example, when the MAPE, RMSE and MAE are $1.18 \%, 0.0065$, 0.0052 at $\mathrm{h} / \mathrm{c}=0.7,1.42 \%, 0.0082,0.0065$ at $\mathrm{h} / \mathrm{c}=0.55$, they equal to $2.57 \%, 0.0136,0.0123$ at $h / c=0.1$, respectively. This situation can be attributed to the more unsteady, complex, and disorganized flow structures by reducing the normalized ground distance, $h / c$ between wing and ground surface. These complex and disorganized flow structures may cause sudden changes in aerodynamic forces and fluctuations in the values of aerodynamic forces.

Table 2. The values of MAPE, RMSE, and MAE for the estimation of lift coefficient, $C_{L}$ during training case including all $\mathrm{h} / \mathrm{c}$

\begin{tabular}{|c|c|c|}
\hline \multicolumn{3}{|c|}{ TRAINING (including all cases) } \\
\hline MAPE & RMSE & MAE \\
\hline $1.77 \%$ & 0.01 & 0.0080 \\
\hline
\end{tabular}

Table 3. The values of MAPE, RMSE, and MAE for the estimation of lift coefficient, $C_{L}$ during training case for $h / c=1,0.7,0.55,0.25$ and 0.1 separately

\begin{tabular}{|c|c|c|c|}
\hline & \multicolumn{3}{|c|}{ TRAINING } \\
\hline Ground distance & MAPE & RMSE & MAE \\
\hline$h / c=1$ & $1.91 \%$ & 0.0089 & 0.0076 \\
\hline$h / c=0.7$ & $1.18 \%$ & 0.0065 & 0.0052 \\
\hline$h / c=0.55$ & $1.42 \%$ & 0.0082 & 0.0065 \\
\hline$h / c=0.25$ & $1.76 \%$ & 0.0110 & 0.0083 \\
\hline$h / c=0.1$ & $2.57 \%$ & 0.0136 & 0.0123 \\
\hline
\end{tabular}



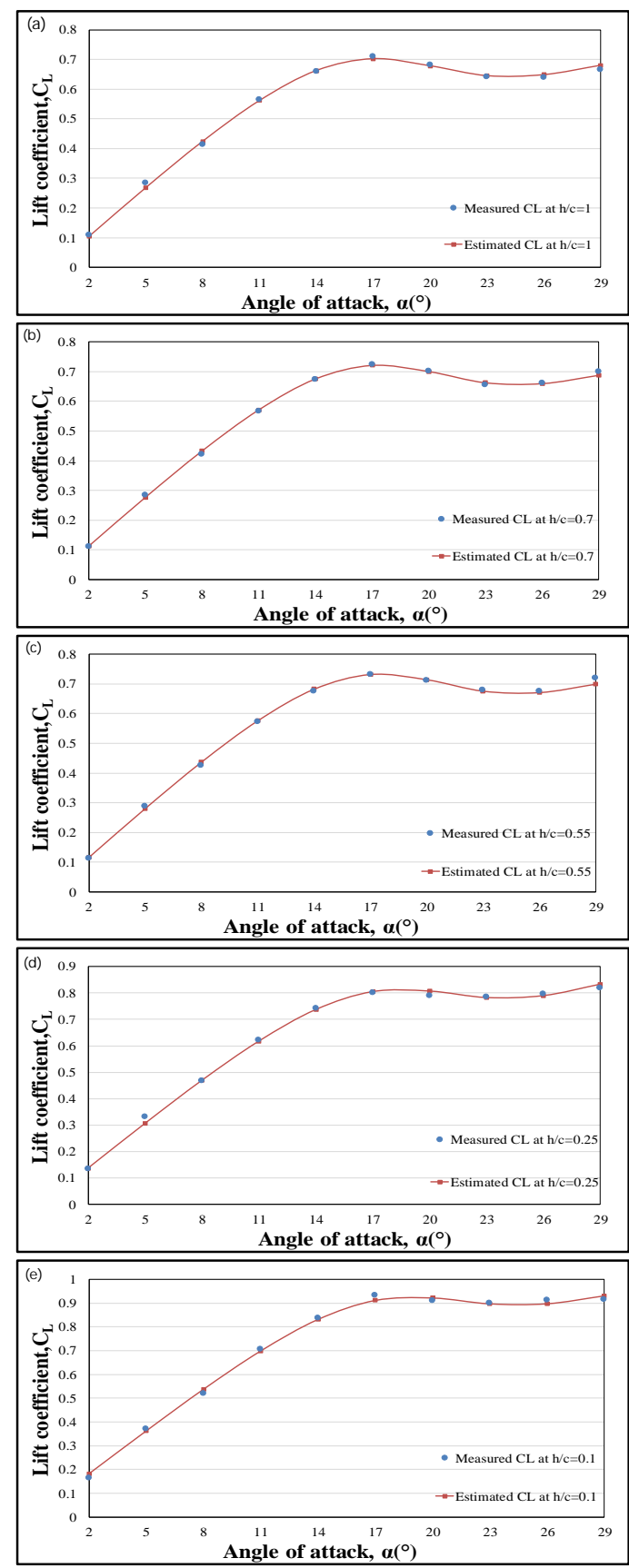

Figure 5. Comparison of actual and predicted lift coefficients, $C_{L}$ of a non-slender delta wing in case of ground distance, a) $h / c=1$, b) $h / c=0.7$, c) $h / c=0.55$, d) $h / c=0.25$, e) $h / c=0.1$ during training process
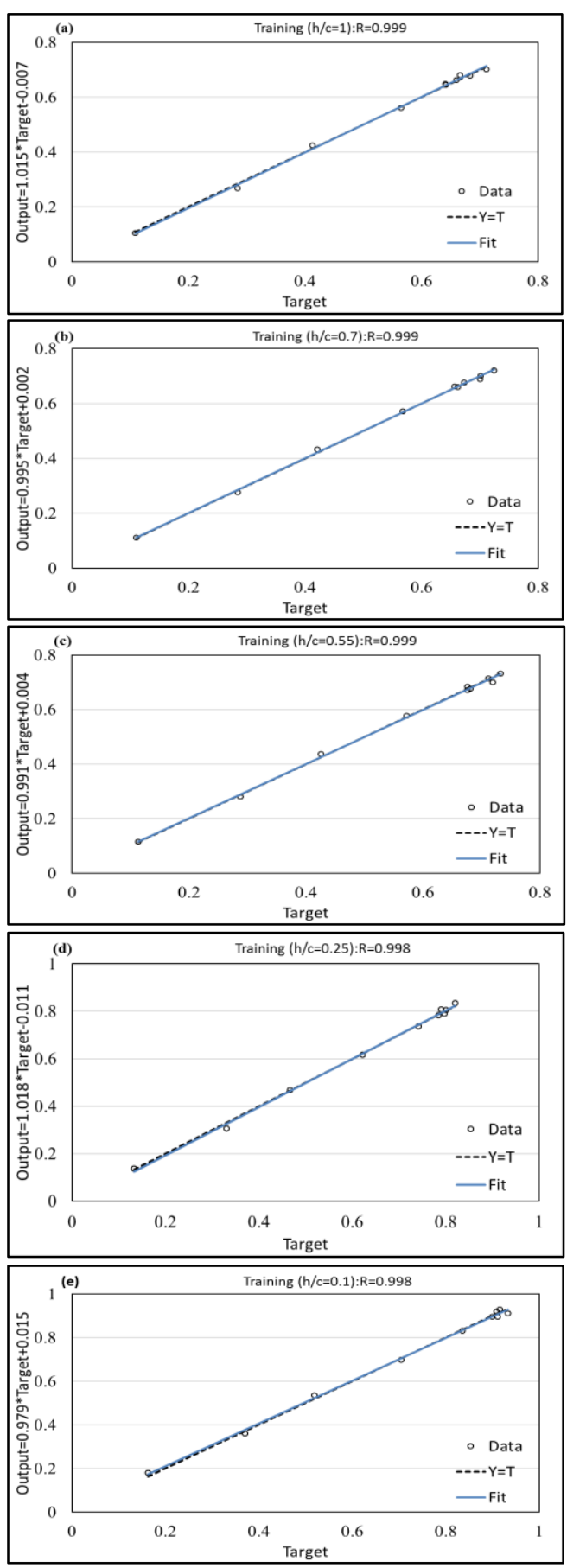

Figure 6. Relation between actual and predicted values of lift coefficient, $C_{L}$ for training case of a) $h / c=1$, b) $h / c=0.7$, c) $h / c=0.55$, d) $h / c=0.25$, e) $h / c=0.1$ 


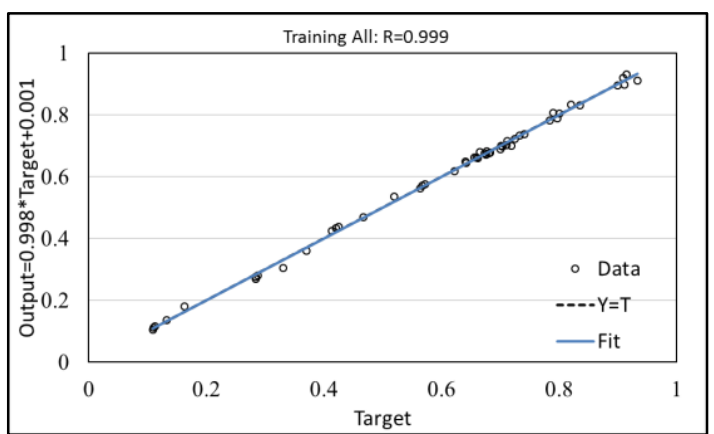

Figure 7. Relation between actual and predicted values of lift coefficient, $C_{L}$ for training case including all $h / c$

\section{CONCLUSIONS}

The available experimental results were presented to reveal the ground effect on the change of lift coefficient, $C_{L}$ of a non-slender delta wing. The purpose of the current study is to improve a model that can be used to predict lift coefficient, $C_{L}$ acting on the non-slender delta wing under the ground effect by utilizing the input parameters of normalized ground distance, $h / c$, and angle of attack, $\alpha$. The conclusions acquired with the ANN model are compared with each other and measured (actual) data. The founded error values are within reasonable limits. For example, the MAPE, RMSE, and MAE values are found as $1.60 \%, 0.0114$ and 0.0086 respectively for the estimation of lift coefficient, $C_{L}$ in case of normalized ground distance, $h / c=0.4$ during the testing case. The prediction of lift coefficient, $C_{L}$ with the ANN model, follows the change of experimentally measured values exactly in the testing stage. The MAPE value in the training stage which consists of the combination of predicted lift coefficients, $C_{L}$ in cases of $h / c=1,0.7,0.55,0.25$, and 0.1 was found as $1.8 \%$, and this value is higher than the MAPE value in the testing stage consisting of $\mathrm{h} / \mathrm{c}=0.4$ which has already computed as $1.6 \%$. In the training stage, the MAPE, RMSE, and MAE values increase with reducing ground distances, $h / c$. For instance, when the MAPE, RMSE and MAE are 1.18\%, 0.0065 and 0.0052 at $\mathrm{h} / \mathrm{c}=0.7$, they are equal to $2.57 \%, 0.0136$ and 0.0123 at $h / c=0.1$ respectively. This situation can be attributed to the more unsteady, complex, and disorganized flow structures by reducing the normalized ground distance, $h / c$ between wing and ground surface. The regression value, $R$ which denotes the relationship between actual and estimated lift coefficients, $C_{L}$ was found as very close to the 1 in training and testing stages which shows the excellent prediction accuracy of the developed ANN model. This study demonstrated that the ANN model could be accurately employed in the aerodynamic coefficient prediction in order to decrease the number of experiments; thus, it is possible to save time and cost

\section{REFERENCES}

1. Gursul, I., Gordnier, R., Visbal, M., 2005. Unsteady Aerodynamics of Nonslender Delta Wings. Progress in Aerospace Sciences, 41(7), 515-557.

2. Ol, M.V., Gharib, M., 2003. Leading-Edge Vortex Structure of Nonslender Delta Wings at Low Reynolds Number. AIAA Journal, 41(1), 16-26.

3. Gursul, I., Allan, M., Badcock, K., 2005. Opportunities for the Integrated Use of Measurements and Computations for the Understanding of Delta Wing Aerodynamics. Aerospace Science and Technology, 9(3), 181189.

4. https://www.grc.nasa.gov/www/k12/airplane/li ftco.html. Erişim Tarihi: 08.06.2021.

5. Kawazoe, H., Morita, S., 2004. Ground Effect on the Dynamic Characteristics of A WingRock Delta Wing. 34 ${ }^{\text {th }}$ AIAA Fluid Dynamics Conference and Exhibit.

6. Lee, T., Tremblay-Dionne, V., Ko, L., 2018. Ground Effect on a Slender Reverse Delta Wing with Anhedral. Proceedings of the Institution of Mechanical Engineers, Part G: Journal of Aerospace Engineering, 233(4), 1516-1525.

7. Tumse, S., Tasci, M. O., Karasu, I., Sahin, B., 2021. Effect of Ground on Flow Characteristics and Aerodynamic Performance of a Nonslender Delta Wing. Aerospace Science and Technology, 110, 106475.

8. Lee, T., Ko, L. S., 2018. Ground Effect on the Vortex Flow and Aerodynamics of a Slender Delta Wing. Journal of Fluids Engineering, 140(7). 
9. Qu, Q., Lu, Z., Guo, H., Liu, P., Agarwal, R. K., 2015. Numerical Investigation of the Aerodynamics of a Delta Wing in Ground Effect. Journal of Aircraft, 52(1), 329-340.

10. Ahmed, M.R., Takasaki, T., Kohama, Y., 2007. Aerodynamics of a NACA4412 Airfoil in Ground Effect. AIAA Journal, 45(1), 37-47.

11. Narendra, K., Parthasarathy, K., 1990. Identification and Control of Dynamical Systems Using Neural Networks. IEEE Transactions on Neural Networks, 1(1), 4-27.

12. Hunt, K., Sbarbaro, D., Zbikowski, R., Gawthrop, P., 1992. Neural Networks for Control Systems-A Survey. Automatica, 28(6), 1083-1112.

13. Calise, A.J., Rysdyk., R.T., 1998. Nonlinear Adaptive Flight Control Using Neural Networks. IEEE Control Systems Magazine, 18, 14-25

14. Gim, Y., Jang, D.K., Sohn, D.K., Kim, H., Ko, H.S., 2020. Three-dimensional Particle Tracking Velocimetry Using Shallow Neural Network for Real-time Analysis. Experiments in Fluids, 61(2).

15. Rabault, J., Kolaas, J., Jensen, A., 2017. Performing Particle Image Velocimetry Using Artificial Neural Networks: A Proof-ofConcept. Measurement Science and Technology, 28(12), 1-14.

16. Cai, S., Liang, J., Gao, Q., Xu, C., Wei, R., 2020. Particle Image Velocimetry Based on a Deep Learning Motion Estimator. IEEE Transactions on Instrumentation and Measurement, 69(6), 3538-3554.

17. Rabault, J., Kuhnle, A., 2019. Accelerating Deep Reinforcement Learning Strategies of Flow Control through a Multi-environment Approach. Physics of Fluids, 31(9), 094105.

18. Tang, H., Rabault, J., Kuhnle, A., Wang, Y., Wang, T., 2020. Robust Active Flow Control over a range of Reynolds Numbers Using an Artificial Neural Network Trained Through Deep Reinforcement Learning. Physics of Fluids, 32(5), 053605.

19. Belus, V., Rabault, J., Viquerat, J., Che, Z., Hachem, E., Reglade, U., 2019. Exploiting Locality and Translational Invariance to Design Effective Deep Reinforcement Learning
Control of the 1-Dimensional Unstable Falling Liquid Film. AIP Advances, 9(12), 125014.

20. Akbiyik, H., Yavuz, H., 2021. Artificial Neural Network Application for Aerodynamics of an Airfoil Equipped with Plasma Actuators. Journal of Applied Fluid Mechanics, 14(4), 1165-1181.

21. Akansu, Y.E., Sarıoglu, M., Seyhan, M., 2016. Aerodynamic Drag Force Estimation of a Truck Trailer Model Using Artificial Neural Network. International Journal of Automotive Engineering and Technologies, 5(4), 168-175.

22. Rokhsaz, K., Steck, J.E., 1993. Use of Neural Networks in Control of High-alpha Maneuvers. Journal of Guidance, Control, and Dynamics, 16(5), 934-939.

23. Rokhsaz, K., Steck, J.E., 1993. Application of Artificial Neural Networks in Nonlinear Aerodynamics and Aircraft Design. SAE Technical Paper Series.

24. Alkhedher, M., Al-Aribe, Khaled., 2019. Estimation and Prediction of Nonlinear Aerodynamics using Artificial Intelligence. $7^{\text {th }}$ International Conference on Future Internet of Things and Cloud Workshops (FiCloudW).

25. Gomec, F.S., Canibek, M., 2017. Aerodynamic Database Improvement of Aircraft Based on Neural Networks and Genetic Algorithms. $7^{\text {th }}$ European Conference for Aeronautics and Space Sciences (Eucass).

26. Ignatyev, D., Khrabrov, A., 2018. Experimental Study and Neural Network Modeling of Aerodynamic Characteristics of Canard Aircraft at High Angles of Attack. Aerospace, 5(1), 26.

27.Secco, N.R., Mattos, B.S., 2017. Artificial Neural Networks to Predict Aerodynamic Coefficients of Transport Airplanes. Aircraft Engineering and Aerospace Technology, 89(2), 211-230.

28. Rai, M.M., Madavan, N.K., 2001. Application of Artificial Neural Networks to the Design of Turbomachinery Airfoils. Journal of Propulsion and Power, 17(1), 176-183.

29. Akbiyik, H., Yavuz, H., 2020. Dbd Plazma Aktüatör Sürüm Frekansının Uçak Kanadı Etrafındaki Akışın Kontrolüne Etkisinin İncelenmesi. Konya Journal of Engineering Sciences, 8(3), 522-528. 
30. Akbiyik, H., Yavuz, H., Akansu, Y.E., 2017. Comparison of the Linear and SpanwiseSegmented Dbd Plasma Actuators on Flow Control around a Naca0015 Airfoil. IEEE Transactions on Plasma Science, 45(11), 29132921.

31. Bishop, C.M., 1994. Neural Networks and Their Applications. Review of Scientific Instruments, 65, 1803-1832.

32. Ozbek, A., 2016. Yapay Sinir Ağları Kullanarak Nemli Havanın Termodinamik Özelliklerinin Tahmini. Çukurova Üniversitesi MühendislikMimarlık Fakültesi Dergisi, 31(1), 51-58.

33. Hosoz, M., Ertunc, H.M., Bulgurcu, H., 2007. Performance Prediction of a Cooling Tower Using Artificial Neural Network. Energy Conversion and Management, 48(4), 13491359.

34. Senkal, O., 2016. Yapay Sinir Ağları ile Atmosferik Parametreler Kullanılarak Türkiye için Güneş Radyasyonu Modellemesi. Çukurova Üniversitesi Mühendislik-Mimarlık Fakültesi Dergisi, 31(2), 179-186.

35. Lewis, C.D., 1982. Industrial and Business Forecasting Methods. Butterworth Scientific, London. 